\title{
Ondel-ondel kekinian: boneka besar Betawi di zaman modern
}

\author{
Mita Purbasari, ${ }^{1 *}$ M Dwi Marianto, ${ }^{2}$ M Agus Burhan ${ }^{2}$ \\ ${ }^{1}$ Program Studi Desain Komunikasi Visual, Universitas Bina Nusantara, Jakarta, Indonesia \\ ${ }^{2}$ Program Studi Seni Murni, Institut Seni Indonesia, Yogyakarta, Indonesia
}

\begin{abstract}
Ondel-ondel is an ancient Betawi's art work named Barongan, in simple shaped of one pair off greater puppets, complete with the music companion. At the beginning, ondel-ondel was a part of Betawinese scared rituals then become one of Jakarta's icons. Ondel-ondel can be found until today either in performing arts and decoration element form. In its development as the decoration element form, ondel-ondel is not only the great puppet for buildings and stages decorator, but also has been positioned as a part of cultural tourism and society living needs. Moreover, ondel-ondel has been used to be an inspiration to produce souvenir to support industry. Ondel-ondel is not longer just made in big size, but also in mini size in form of 2 or 3 dimensions, so it is easy to be carried as a souvenir, which represents Jakarta and Betawi. To find out the value behind the sign changed, this qualitative research used the semiotic approach. Connection or relation between symbolic sign in ondel-ondel structure and building elements were collaborated with society condition as the background and impact of the society on that time to get the value. The changes of ondel-ondel's meanings and functions in building elements have been produced and contracted as its user way of thinking based on its form and context. The meaning interpretation of ondel-ondel craftsman and audience in particular time would be different with government's policies.
\end{abstract}

Key words: ondel-ondel, building elements, souvenir, meaning, function

\begin{abstract}
Abstrak
Ondel-ondel adalah hasil karya seni Betawi kuno bernama Barongan, berupa sepasang boneka raksasa berbentuk sederhana, lengkap dengan tim musik pengiring. Pada awalnya ondel-ondel merupakan bagian dari aktivitas ritual sakral rakyat yang kemudian dijadikan sebagai salah satu ikon kota Jakarta. Sampai dengan hari ini ondel-ondel masih dapat ditemui, baik dalam bentuk seni pertunjukan maupun elemen dekorasi. Dalam perkembangannya sebagai elemen dekorasi, ondel-ondel tidak hanya menjadi boneka besar penghias gedung dan panggung acara saja, namun diposisikan sebagai bagian dari wisata budaya serta sebagaipemenuhan hidup masyarakat. Selain itu, ternyata ondel-ondel telah menjadi inspirasi untuk dijadikan produk cenderamata pendukung industri. Tidak lagi hanya dibuat dalam ukuran besar, ondel-ondel juga dibuat berukuran kecil dalam wujud 2 ataupun 3 dimensi sehingga cocok dibawa sebagai buah tangan yang mewakili Jakarta dan Betawi. Untuk melihat makna dibalik tanda-tanda perubahan yang terjadi, penelitian kualitatif ini menggunakan pendekatan semiotika. Hubungan atau relasi antar tanda simbolik yang ada pada struktur dan unsur-unsur pembentuk ondel-ondel dikolaborasikan dengan kondisi masyarakat sebagai latar belakang dan dampaknya dalam masyarakat saat ini untuk mendapatkan makna. Perubahan makna dan fungsi ondel-ondel pada unsur-unsur pembentuknya diproduksi dan dikonstruksi sebagai mental pemikiran penggunanya berdasarkan bentuk dan konteksnya. Interpretasi makna pengrajin dan penikmat ondel-ondel pada saat tertentu akan berbeda dengan aksi kebijakan yang diberikan oleh pemerintah.
\end{abstract}

Kata kunci: ondel-ondel, unsur-unsur pembentuk, cinderamata, makna, fungsi

\section{Pendahuluan}

Ondel-ondel adalah boneka besar khas Betawi yang sudah ada dan digunakan sejak zaman penjajahan Belanda oleh Pangeran Jayakarta Wijaya Karma dalam iring-iringan upacara sunatan raja Banten, Abdul Mafakhir pada tahun 1605 (Mees, 1920: 6466). Saputra mengatakan bahwa ondel-ondel mempresentasikan kebudayaan Betawi Kuno yang awalnya merupakan bagian dari aktivitas ritual sakral

\footnotetext{
* Corresponding author Tel : +62-878-7887-7654 ; e-mail : mitawahid@binus.edu
} 
rakyat. Ondel-ondel semula bernama barung, kemudian menjadi barongan, artinya dalam bahasa Betawi adalah sekelompok atau serombongan orang karena barongan bukan kesenian yang bisa dimainkan sendiri (Wawancara, 22 Mei 2013). Barongan dibuat saat masyarakat Betawi Pinggir masih bergelut di sektor agraris. Namun seiring perjalanan waktu, manakala sektor industri dan jasa hiburan memasuki ranah Jakarta, maka pada tahun 1970-an Ali Sadikin, Gubernur Jakarta saat itu, mencanangkan ondel-ondel sebagai ikon Jakarta (Samantha, 2013). Kini ondelondel kembali dihadirkan dalam kehidupan masyarakat Betawi baik dalam bentuk seni pertunjukan maupun dekorasi.

Boneka besar ini berukuran 250 x 80 x $80 \mathrm{~cm}$ dengan bahan kerangka dari rotan atau bambu, dengan topeng dari kayu berkualitas baik, seperti kayu cempaka, kenanga, rambutan atau kapuk (Saputra, 2009: 60). Pemilihan kayu berkualitas baik untuk topeng ondel-ondel menandakan bahwa pada masa itu ondel-ondel atau barongan merupakan karya seni yang memiliki tempat baik di mata masyarakat. Selain itu juga menceritakan bahwa dahulu kala masyarakat Betawi dekat dengan alam serta memanfaatkan alam sekitarnya dengan baik. Pemanfaatan kayu-kayu tersebut menggambarkan Jakarta memiliki tanah yang luas di mana pohonpohon tersebut dapat tumbuh subur dan besar di sana. Barongan dibuat berpasangan laki-laki dan perempuan

Pada dasarnya, ondel-ondel memiliki struktur dan unsur-unsur pembentuk yang hampir sama dari zaman ke zaman. Berdasarkan penelitian penelitian Istiqoma pada tahun 2013 mengenai pengenalan kesenian ondel-ondel melalui media board game, peneliti membuat struktur dan unsur-unsur pembentuk pada ondel-ondel lebih rinci dan detail.

Shahab (2001) dalam penelitiannya mengenai rekacipta tradisi Betawi mengatakan bahwa ondelondel merupakan salah satu seni tradisi Betawi yang mengalami proses nasionalisasi. Pernyataan Shahab di atas menegaskan bahwa ondel-ondel banyak mengalami perubahan untuk diakui dan diterima sebagai seni Betawi, terlebih lagi terpilihnya ondelondel menjadi ikon kota Jakarta. Dapat dikatakan bahwa ondel-ondel merupakan hasil negosiasi paksa kaum elit Betawi (penguasa/pemerintah dan tokoh agama yang tidak memiliki keahlian dalam seni) dengan organisasi-organisasi kesenian Betawi.

Penelitian oleh Lissandhi (2010) mengenai ondelondel menjelaskan bahwa perubahan budaya dan pergerakan dalam masyarakat Betawi yang didominasi oleh Muslim mampu membawa ondelondel menjadi salah satu identitas budaya yang terus diubah sesuai dengan kepentingannya. Penelitian ini menitikberatkan pada ondel-ondel sebagai artefak seni lama yang mampu menjadi identitas budaya dan melewati proses panjang perubahan zaman (politik, ekonomi, sosial, budaya) secara umum termasuk masalah dan pertentangan yang didapat dari masyarakat Betawi Kota.

Berdasarkan data di atas, dapat dikatakan bahwa ondel-ondel adalah boneka besar khas Betawi yang memiliki keunikan khusus. Kemunculan boneka besar ini dalam masyarakat Betawi diposisikan sebagai mahluk baik penjaga kampung, ondel-ondel mampu membuat suasana meriah dengan segala asesoris, gaya dan musik pengiringnya.

Keberadaan ondel-ondel yang telah berumur panjang dan hampir selalu muncul di setiap kegiatan masyarakat Betawi sampai dengan hari ini (kecuali upacara kematian), membuktikan bahwa ondel-ondel memiliki signifikansi yang jelas di berbagai dimensi kehidupan masyarakat Betawi. Dengan bentuk dasar yang sederhana, ondel-ondel berhasil menarik perhatian banyak orang dalam setiap pengarakannya.

Masyarakat terpanggil oleh alunan musik pengiring ondel-ondel yang meriah dan ramai, ditambah dengan pertunjukan ondel-ondel menari-nari. Ondel-ondel banyak digunakan untuk menambah semarak pestapesta rakyat seperti sunatan, pernikahan, ulang tahun kota Jakata, karnaval, dan lain sebagainya bahkan juga sebagai penerima tamu kehormatan dalam peresmian gedung yang baru dibangun. Kemeriahan pengarakan ondel-ondel menjadi tempat masyarakat Betawi bertemu dan bersosialisasi.

Dalam perkembangan selanjutnya, fenomena yang terjadi adalah ondel-ondel tidak lagi dikaitkan sebagai objek sakral tetapi berkembang menjadi bagian dari beberapa bentuk seni tradisi, dan menjadi media untuk berbagai kepentingan praktis termasuk menjadi sekedar properti negara yang digunakan untuk kepentingan bisnis besar dan kecil. Sebagai seni dekorasi, ondel-ondel tidak hanya digunakan sebagai alat penghias gedung (penjaga pintu gedung dan penerima tamu) dan panggung kesenian maupun non kesenian saja (Gambar 1 dan 2), namun juga diposisikan sebagai bagian dari wisata budaya serta pemenuhan kebutuhan hidup masyarakatnya.

Saat ini, ondel-ondel juga menjadi inspirasi untuk dijadikan produk cinderamata pendukung industri. Ondel-ondel diproduksi dalam ukuran kecil dengan wujud 2 dan 3 dimensi sehingga cocok untuk dibawa sebagai buah tangan yang mewakili kota DKI Jakarta dan masyarakat Betawi.

Perubahan fungsi dan makna ondel-ondel dari sebuah media wisata budaya menjadi produk yang mendukung wisata budaya, dimana dengan ukuran 
yang lebih kecil menjadi mudah dibawa dan mengingatkan orang akan tempat yang pernah dikunjunginya. Ondel-ondel tidak lagi diproduksi sepasang atau beberapa pasang saja, namun bisa menjadi produk masal yang dapat dengan mudah dimiliki semua orang. Perubahannya dari objek sakral menjadi wisata budaya dan kemudian menjadi produk masal pendukung wisata budaya, memberikan dampak yang luar biasa terhadap keberadaan ondelondel dalam mempertahankan kelangsungan hidup seni tradisi dan masyarakatnya dalam globalisasi.

Penelitian ini dilakukan untuk melihat perubahan, fungsi dan makna simbolik unsur-unsur pembentuk pada ondel-ondel sebagai ondel-ondel dekorasi dan ondel-ondel cinderamata. Diharapkan dengan mengetahui perubahan pada unsur-unsur pembentuk ini, maka masyarakat Betawi dapat menghargai ondelondel sebagai ikon Jakarta dengan layak. Unsur-unsur pembentuknya dapat tetap dijaga keberadaannya sebagai identitas diri boneka besar khas Betawi.

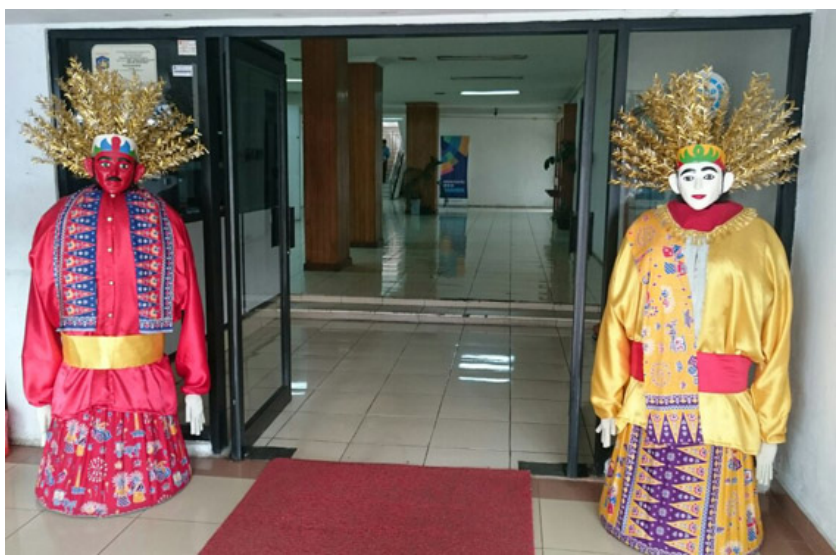

Gambar 1. Ondel-Ondel Penjaga Pintu Gedung Dinas Perindustrian dan Energi DKI Jakarta, 3 Mei 2018. Sumber: Purbasari

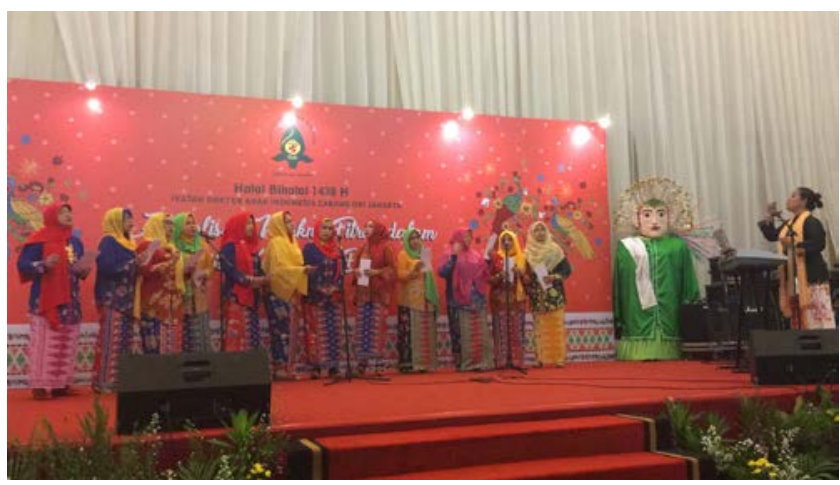

Gambar 2. Ondel-Ondel penghias panggung halal bihalal IDAI DKI Jakarta, Mampang. Sumber: Purbasari 2017

\section{Bahan dan metode}

Penelitian ini menggunakan metode kualitatif dengan pendekatan analisis semiotika, menyajikan dinamika perubahan masyarakat Betawi melalui konteks ondel-ondel untuk menjelaskan fenomena yang memiliki nilai budaya.

Proses pengumpulan data dilakukan dengan sistematis dan deskriptif, untuk melihat sistem struktur hubungan antara objek (unsur-unsur pembentuk pada ondel-ondel) dengan kehidupan masyarakatnya pada saat itu. Metode ini dilakukan untuk membongkar struktur budaya Betawi (ondelondel) dan melihat hubungannya. Penelitian ini fokus pada perubahan pada unsur-unsur pembentuk pada ondel-ondel sebagai boneka besar untuk wisata budaya dengan ondel-ondel sebagai produk pendukung wisata budaya.

Sebagai sebuah penelitian semiotika, penelitian ini mengamati boneka besar khas Betawi, dimulai dari tahun 2012 hingga 2018, dimana ondel-ondel telah banyak digunakan sebagai pendukung wisata budaya atau cinderamata.

Tahapan penelitian ini adalah:

1. Pengumpulan data yang berhubungan dengan objek (ondel-ondel) dan subjek (konsep dan aktivitas sosial kultural masyarakat Betawi).

2. Observasi, wawancara dan dokumentasi dari kegiatan masyarakat Betawi yang berhubungan dengan ondel-ondel selama 2012-2018. Sumber data diperoleh dari ahli sejarah dan humanis, Yahya Andi Saputra) mengenai makna simbolik di setiap unsur-unsur pembentuk pada ondel-ondel, pengrajin ondel-ondel dan masyarakat Betawi itu sendiri.

3. Setiap perubahan atau transformasi ondel-ondel dianalisa dan distruktur dengan menggunakan analisis semiotika untuk melihat hubungan antara unsur-unsur pembentuk ondel-ondel, budaya dan masyarakat.

4. Hubungan antara proses metafor dan semiotika dalam konteks di atas, digunakan untuk merepresentasikan konsep budaya Betawi melalui ondel-ondel.

Semiotika mengenai bentuk (form), konten (content), dan konteks (context) dipilih untuk menganalisa struktur dari unsur-unsur pembentuk ondel-ondel. Bentuk merupakan unsur-unsur atau elemen-elemen pembentuk dari struktur ondel-ondel. Konten merupakan pesan atau arti dari bentuk tadi, dan konteks merupakan variasi atau ragam kondisi dimana objek tersebut diproduksi dan ditafsir oleh orang lain. Makna simbolik dan dan fungsi unsur- 
unsur pembentuk pada ondel-ondel telah dibentuk sebagai penambah nilai dari ondel-ondel itu sendiri (Danesi, 2004).

\section{Hasil dan pembahasan}

Sepasang ondel-ondel, pria dan wanita memiliki bentuk struktur yang sama, perbedaannya terdapat pada detail dalam unsur-unsur pembentuknya. Secara garis besar, struktur ondel-ondel terbagi atas 3 bagian besar, yaitu kepala (atas), badan (tengah), dan kaki (bawah). Bagian kepala terdapat unsur-unsur pembentuk: kembang kelapa, stangan (mahkota), rambut yang terbuat dari ijuk dan topeng (wajah) yang terbuat dari kayu pilihan atau fiber. Bagian badan terdiri dari unsur-unsur pembentuk: ondelondel pria: cukin (kain sarung yang menghiasi leher), baju sadariah (baju Betawi muslim) dan ikat pinggang. Pada ondel-ondel wanita terdapat selempang atau selendang yang melintasi dada dari bahu kiri ke pinggang kanan, toka-toka (penghias leher berhiaskan manik-manik merah), baju kurung atau kebaya dan ikat pinggang kain berwarna cerah. Bagian terakhir adalah bagian bawah, terdapat kain sarung terkenal dengan sebutan kain jamblang, untuk menutupi bagian bawah ondel-ondel (Gambar 3).

Struktur dan unsur-unsur kostum sepasang ondelondel ini merupakan bagian dasar yang didapat dari hasil literatur, pengamatan langsung dan wawancara dengan Saputra, 3 Juni 2013. Ondel-ondel memiliki paduan warna-warna cerah dengan tingkat kontras yang tinggi. Tidak ada ketentuan warna yang harus digunakan oleh ondel-ondel namun penggunaan komposisi saling bertabrakan merupakan ciri khas dalam warna Betawi.

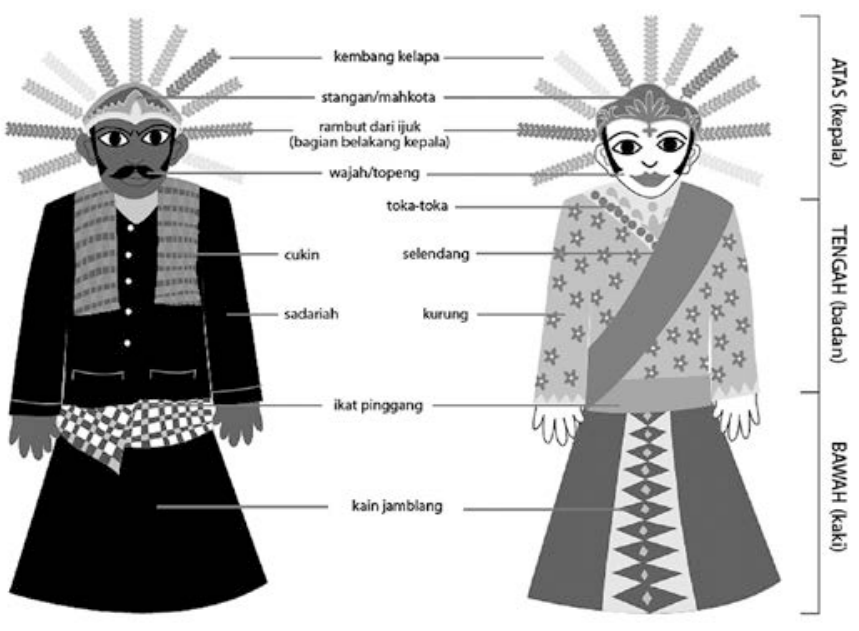

Gambar 3. Struktur dan unsur-unsur pembentuk Ondel-ondel Sumber: Purbasari, 2013
Warna Betawi yang paling sering muncul dalam ondel-ondel adalah: dadu (merah), jambon, oren, kuning, hijau, biru, hitam dan putih. Kedelapan warna-warna tersebut dikombinasikan bertabrakan untuk menimbulkan kesan meriah, seronok, dan menarik perhatian (Purbasari, 2016).

Di masa berkembangnya sektor pariwisata dan perdagangan, ikon kota Jakarta ini tidak hanya digunakan sebagai bagian dari wisata budaya, namun juga sebagai objek pendukung wisata budaya. Ondelondel kini banyak diproduksi secara masal sebagai

Tabel 1. Unsur-unsur pembentuk pada Ondel-ondel ${ }^{\mathrm{a}}$

\begin{tabular}{|c|c|c|}
\hline $\begin{array}{c}\text { Unsur } \\
\text { Pembentuk }\end{array}$ & $\begin{array}{l}\text { Kedudukan dalam } \\
\text { Struktur Onde-ondel }\end{array}$ & Keterangan \\
\hline $\begin{array}{l}\text { Kembang } \\
\text { Kelapa }\end{array}$ & Penghias kepala & $\begin{array}{l}\text { Tumbuhan kelapa yang tidak ada } \\
\text { bagian yang terbuah. Artinya } \\
\text { orang yang siap memberikan } \\
\text { hasil guna karyanya berdasarkan } \\
\text { daya dan kemampuan }\end{array}$ \\
\hline Stangan & Mahkota & Penghias kepala ondel-ondel. \\
\hline Ijuk & Rambut & $\begin{array}{l}\text { Penutup bagian kepala, tempat } \\
\text { kembang kelapa diletakan. }\end{array}$ \\
\hline Topeng & Wajah & $\begin{array}{l}\text { Ondel-ondel pria berwarna } \\
\text { merah atau hitam (gelap), } \\
\text { memberi kesan berani, seram, } \\
\text { menakutkan. } \\
\text { Ondel-ondel wanita berwarna } \\
\text { putih (terang) memberikan kesan } \\
\text { lembut, suci, keibuan. }\end{array}$ \\
\hline Toka-toka & $\begin{array}{l}\text { Hiasan penutup dada } \\
\text { pada ondel-ondel } \\
\text { wanita }\end{array}$ & $\begin{array}{l}\text { Bentuknya beraneka ragam, } \\
\text { tidak terpaku pada segitiga saja. } \\
\text { Terdapat hiasan manik-manik } \\
\text { biji buah delima, sebagai simbol } \\
\text { rejeki lancar. }\end{array}$ \\
\hline \multirow[t]{2}{*}{$\begin{array}{l}\text { Cukin - } \\
\text { Selempang }\end{array}$} & $\begin{array}{l}\text { Hiasan dada pada } \\
\text { ondel-ondel pria }\end{array}$ & $\begin{array}{l}\text { Cukin: kain yang digantungkan } \\
\text { pada leher ondel-ondel pria. } \\
\text { Biasa digunakan oleh murid } \\
\text { pesantren dan si Pitung, sebagai } \\
\text { simbol keislaman. }\end{array}$ \\
\hline & & $\begin{array}{l}\text { Selempang: kain yang } \\
\text { diselempangkan dari pundak kiri } \\
\text { ke pinggang kanan. Artinya } \\
\text { hidup manusia cenderung salah } \\
\text { arah (kiri), namun harus digiring } \\
\text { ke arah kanan. }\end{array}$ \\
\hline $\begin{array}{l}\text { Sadariah dan } \\
\text { Kurung / } \\
\text { Kebaya }\end{array}$ & Pakaian & $\begin{array}{l}\text { Sadarian: pakaian ondel-ondel } \\
\text { pria. Kurung dan kebaya pakaian } \\
\text { ondel-ondel wanita. }\end{array}$ \\
\hline $\begin{array}{l}\text { Kain pada } \\
\text { Pinggang }\end{array}$ & Ikat Pinggang & $\begin{array}{l}\text { Kain yang melilit pada bagian } \\
\text { pinggang ondel-ondel }\end{array}$ \\
\hline $\begin{array}{l}\text { Kain } \\
\text { Jamblang }\end{array}$ & $\begin{array}{l}\text { Kain bagian bawah } \\
\text { penutup kaki }\end{array}$ & $\begin{array}{l}\text { Kain bawah ondel-ondel pria dan } \\
\text { wanita }\end{array}$ \\
\hline
\end{tabular}

${ }^{\mathrm{a}}$ Hasil pengembangan dari wawancara Yahya Andi Saputra (Wakil Ketua Bidang 3 Lembaga Kebudayaan Betawi), Setu Babakan, 3 Juni 2013 
cinderamata dalam bentuk apapun. Sebagai objek pendukung wisata budaya, ondel-ondel dibentuk tidak hanya dalam format 3 dimensi saja seperti: boneka, pajangan, leontin kalung, namun juga 2 dimensi seperti: motif yang dicetak pada kain atau batik dibuat menjadi aksen pada pakaian, syal, lukisan dan lainnya (Gambar 4 dan 5).

Pada saat ini, struktur ondel-ondel tidak selalu digunakan keseluruhan dari bagian atas (kepala) hingga bawah (kaki). Bagian kepala merupakan bagian yang paling banyak digunakan, karena kepala ondel-ondel memiliki hiasan stangan dan kembang kelapa yang merupakan salah satu ciri khas ondelondel dibandingkan dengan boneka besar lainnya di Indonesia. Dengan alasan pengalihan ke medium yang jauh lebih, maka penggambaran stangan dan kembang kelapa mengalami penyederhanaan, baik dalam bentuk maupun warna. Penggunaan kepala ondelondel untuk membuat cinderamata, misalnya terdapat pada gantungan kunci dan magnet kulkas (Gambar 6).
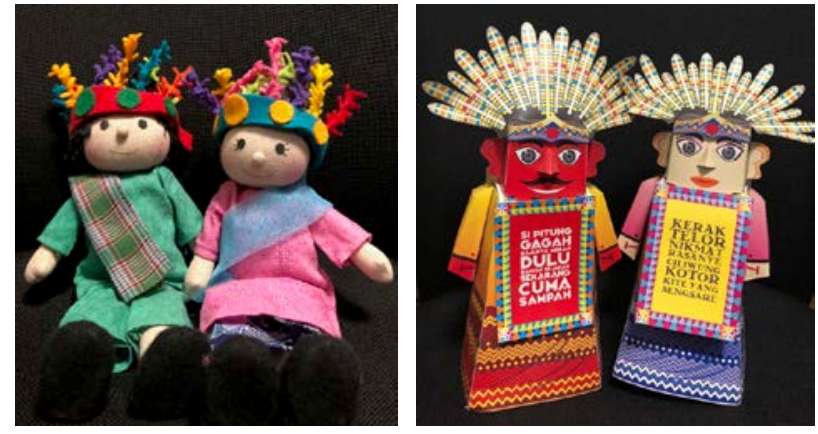

Gambar 4. Ondel-ondel dalam format 3D: boneka dan pajangan Sumber: Purbasari, 2018

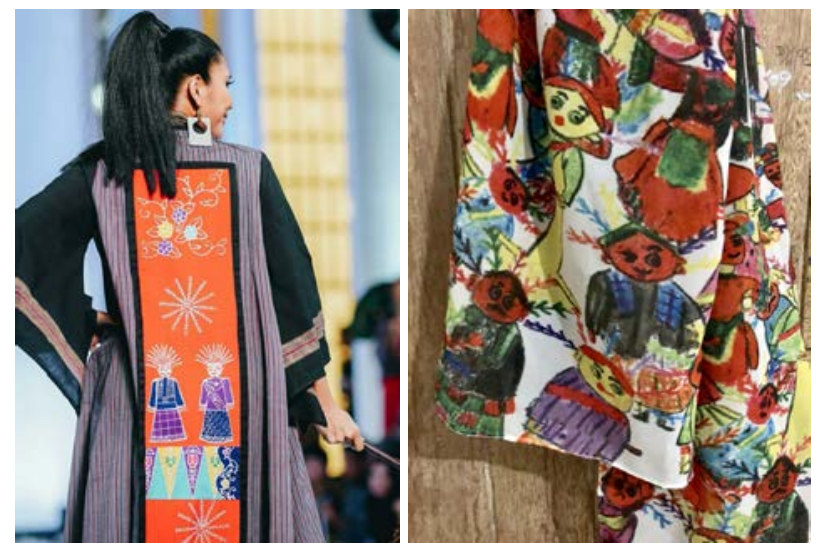

Gambar 5. Ondel-ondel dalam format 2D (motif): aksen pada pakaian dan syal

Sumber: Klambi Abite, 2018 dan Purbasari, 2018
Perkembangan selanjutnya, ondel-ondel tidak hanya digunakan bagian kepalanya saja, namun juga digunakan tanpa pasangan. Hal ini terjadi karena beberapa alasan, antara lain karena seri dalam produknya hanya menggunakan 1 gender saja (wanita), maka hanya digunakan 1 ondel-ondel saja. Alasan lainnya karena belum tentu ada pembeli yang suka dengan salah 1 ondel-ondel, sehingga hanya dibuat 1 ondel-ondel saja (Gambar 7).

Melihat unsur-unsur pembentuk pada ondel-ondel dalam produk-produk cinderamata ini, maka terjadi perubahan yang cukup signifikan, bukan karena hanya perubahan medium dan ukuran saja, namun juga terjadi perubahan makna simbolik. Beberapa unsur pembentuk pada ondel-ondel yang mengalami perubahan adalah:

Kembang kelapa, terjadi penyederhaan yang cukup drastis, baik dalam bentuk maupun warna.
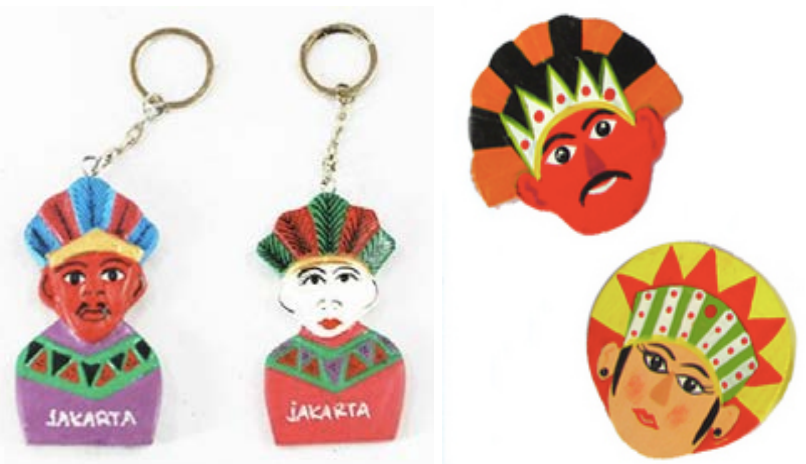

Gambar 6. Kepala Ondel-ondel sebagai gantungan kunci dan magnet kulkas. Sumber: Purbasari, 2018
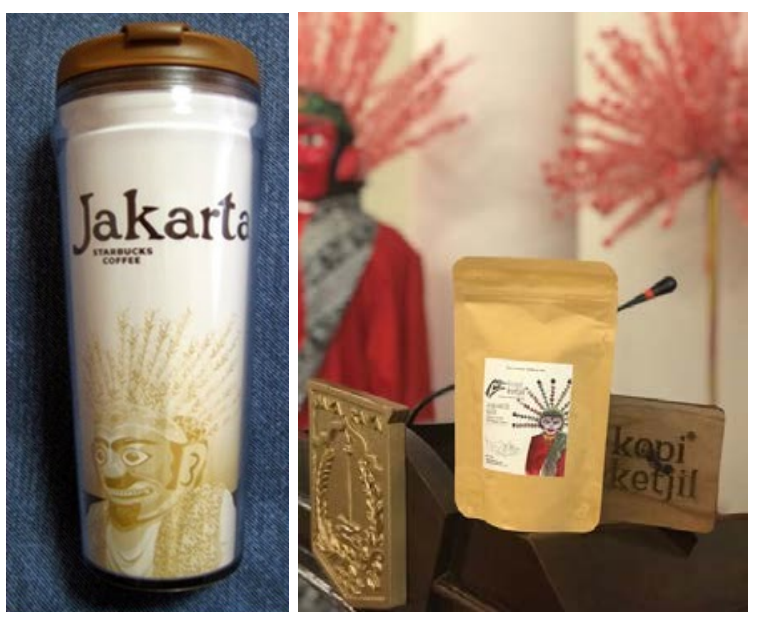

Gambar 7. Ondel-ondel tanpa pasangan digunakan pada produk Sumber: Purbasari, 2018 
1. Penyederhanan ini terjadi karena faktor teknik produksi agar lebih praktis, cepat dan murah.

2. Stangan, dibuat tanpa detail ornamen, hanya berupa garis tipis atau tebal tanpa hiasan yang berarti.

3. Topeng, warna wajah ondel-ondel pria tidak berwarna merah.

4. Toka-toka, ondel-ondel wanita tanpa toka-toka, dan ada ondel-ondel pria mengenakan toka-toka.

5. Cukin, selempang atau selendang, ada ondel-ondel pria tidak menggunakan cukin ataupun selempang. Selempang atau selendang digunakan dengan arah yang tidak seharusnya.

Perubahan unsur-unsur pembentuk pada ondelondel, terutama dalam bentuk kecil dengan tujuan teknis dan efisiensi, seperti gantungan kunci dan magnet kulkas tidak membuat produk ini dikenali dengan cepat sebagai boneka besar Betawi, ondelondel. Terlebih lagi jika tidak ada keterangan berupa tulisan yang menyatakan bahwa produk ini adalah ondel-ondel atau kota Jakarta.

Bisa jadi hal tersebut disebabkan terbatasnya pengetahuan dan pemahaman desainer yang menciptakan produk-produk yang mengambil inspirasi dari ondel-ondel. Pemahaman mereka mengenai fungsi dan makna struktur beserta unsurunsur pembentuk ondel-ondel mungkin sangat terbatas, sehingga penampilan ondel-ondel menjadi sangat beragam seperti yang saat ini ada di masyarakat.

\section{Kesimpulan}

Ketika ondel-ondel diubah statusnya dari benda sakral untuk ritual pengusir roh jahat menjadi benda umum atau masal untuk pendukung wisata budaya, unsur-unsur pembentuk pada ondel-ondel mengalami perubahan sesuai dengan medium, ukuran dan kepentingannya. Ondel-ondel mengalami perubahan sistem pewarnaan dari kombinasi kontras menjadi bebas, misalnya menjadi monokrom, analogus, dan lain sebagainya. Selain perubahan sistem warna, ondel-ondel juga mengalami perubahan bentuk pada unsur-unsurnya. Penyederhanaan bentuk terjadi dengan alasan teknis, praktis, dan efisiensi.

Pengetahuan mengenai ondel-ondel dalam sejarah, fungsi dan makna unsur-unsur pendukungnya, sebaiknya diketahui oleh seluruh masyarakat Betawi, terutama para desainer produk dan pengrajin ondelondel, sehingga penggunaan unsur-unsur pembentuknya dapat disikapi dengan baik dan bijak. Penyederhanaan bentuk dan unsur-unsurnya tanpa adanya pengetahuan yang baik, dapat mengakibatkan bentuk yang salah sehingga objek tidak lagi terlihat sebagai ondel-ondel, boneka besar khas Betawi.

\section{Daftar pustaka}

Danesi, Marcel. (2004). Messages, Signs, and Meanings: A Basic Textbook in Semiotics and Communication Theory, 3rd ed. Toronto, Canada: Canadian Scholars' Press Inc, 10.

Istiqomah, Nurul. (2013). Pengenalan Kesenian OndelOndel Jakarta Kepada Anak-Anak Melalui Media Permainan: Board Game. http://elib.unikom.ac.id/files/disk1/598/jbptunikomppgdl-nurulistiq-29888-8-unikom_n-i.pdf (diakses 22 September 2014).

Lissandhi, Ayu Nova. (2010). The Artistry of Ondel-Ondel. Indonesian Journal of Social Science. Vol. 2/No.1/Pub 2010-01, 27.

Mess, W. Fruin. (1920). Geschiedenis Van Java Dell 2. Weltervreden: Ruygrok \& Co. Batavia.

Purbasari, Mita. (2016). The Dynamic of Betawi in Colors. $\begin{array}{llll}\text { Mudra vol. } 31 & \text { (3), } 391 .\end{array}$ http://dx.doi.org/10.31091/mudra/v31i3.59.

Samantha, Gloria. (2013). Ondel-Ondel, Simbol Budaya Jakarta yang Kian Menjadi Usang. http://nationalgeographic.co.id/berita/2013/12/ondelondel-simbol-budaya-jakarta-yang-kian-menjadi-usang (diakses 02 Juli 2015).

Saputra, Yahya Andi. (2009). Profil Seni Budaya Betawi. Jakarta: Jakarta City Government Tourism and Culture Office.

Shahab, Yasmine Z. (2001). Rekacipta Tradisi Betawi: Sisi Otoritas dalam Proses Nasionalisasi Tradisi Lokal. Antropologi Indonesia 66, 46-57.

Saputra, Yahya Andi (50), Humanist, Wawancara, 22 Mei 2013, Setu Babakan.

Saputra, Yahya Andi (50), Humanist, Wawancara, 3 Juni 2013, Lembaga Kebudayaan Betawi. 